\title{
Vitamin E Decreases Superoxide Anion Production by Polymorphonuclear Leukocytes
}

\author{
W. A. ENGLE, M. C. YODER, J. L. BAURLEY, AND PAO-LO YU \\ Section of Neonatology at Indiana University, [W.A.E., M.C.Y., J.L.B.] and Department of Medical Genetics, \\ Indiana University $[P-L . Y$.$] , Indianapolis, Indiana$
}

\begin{abstract}
Pharmacologic serum levels of vitamin E administered to low birth weight infants predispose them to infectious complications. We studied in vitro the effect of vitamin $\mathrm{E}$, its vehicle and buffer (Krebs Ringers phosphate glucose) on the ability of human polymorphonuclear leukocytes (PMN) to produce superoxide anion, an oxygen radical important for bacterial killing. We found that superoxide anion production after a 5-min exposure to phorbol myristate acetate was significantly decreased in vitamin E-treated PMN (76 $\left.\pm 15 \mathrm{nM} / 10^{7} \mathrm{PMN}\right)$ compared to vehicle-treated PMN $\left(289 \pm 109 \mathrm{nM} / 10^{7} \mathrm{PMN}\right)$. We also found that significantly decreased superoxide anion production was associated with 5.0 and $10.0 \mathrm{mg} / \mathrm{dl}$ but not with $3.5 \mathrm{mg} / \mathrm{dl}$ vitamin E. Our results support the hypothesis that pharmacologic concentrations of vitamin $E$ depress PMN oxidative activity. (Pediatr Res 23: 245-248, 1988)
\end{abstract}

\section{Abbreviations}

PMN, polymorphonuclear leukocytes

AT, $d l$ - $\alpha$-tocopherol

$\mathrm{V}$, vehicle

KRPG, Krebs-Ringers-phosphate-glucose

LDH, lactate dehydrogenase

PMA, phorbol myristate acetate

NEM, N-ethylmaleimide

Vitamin $\mathrm{E}$, or $\alpha$-tocopherol, is administered to many low birth weight infants in an attempt to decrease the incidence of severe retinopathy of prematurity (1-3) intraventricular hemorrhage (4-6), and possibly mortality (5-7). Recently, pharmacologic levels of vitamin $\mathrm{E}(5 \mathrm{mg} / \mathrm{dl})$ have been associated with an increased risk for sepsis and necrotizing enterocolitis (8). We and others have hypothesized that this increased risk for infectious complications may be related to altered host defenses, specifically polymorphonuclear leukocyte oxygen radical production (8).

In vitro, pharmacologic levels of vitamin $\mathrm{E}$ have been associated with decreased PMN chemotaxis, random migration, and bactericidal activity $(9-11)$. Decreased oxygen radical production by PMN has also been found in the presence of high vitamin $\mathrm{E}$ levels. Baehner et al. (11). demonstrated decreased hydrogen peroxide production but normal superoxide anion production. Shigeoka et al. (12) found that PMN from stressed neonates and treated with high concentrations of vitamin $E$ responded to stimuli with significantly less chemiluminescence (a measure of

Received June 16, 1987; accepted October 27, 1987.

Reprint requests William A. Engle, M.D., Department of Pediatrics, James Whitcomb Riley Hospital for Children, R208, Indiana University School of Medicine, 702 Barnhill Drive, Indianapolis, IN 46223.

Supported in part by Riley Memorial Association Grant 87-7. total oxygen radical generation). To further investigate the depressant effect of pharmacologic levels of vitamin $E$ on PMN oxidative metabolism we have studied superoxide anion production in vitro by PMN exposed to pharmacologic levels of vitamin E.

\section{MATERIALS AND METHODS}

Chemicals. Vitamin E (AT) and its V were graciously supplied by Hoffmann-LaRoche, Inc., Nutley, NJ. The composition of the preparation is identical to that given to neonates in whom an increased risk for sepsis and necrotizing enterocolitis was identified (Table 1). The free tocopherol was used in our experiments because it is the form of vitamin $E$ found in the serum and tissues after administration of various formulations of vitamin E (i.e tocopherol acetate, tocopherol succinate). KRPG (pH 7.4) was the buffer utilized for cell preparation and during the superoxide anion assay. Potassium phosphate buffer $(\mathrm{pH} 7.5)$ was used during the LDH assay. Superoxide dismutase cytochrome C, PMA, NEM, pyruvic acid, nicotinamide adenine dinucleotide, calcium chloride, sodium chloride, magnesium chloride, disodium monophosphate, and potassium chloride were obtained from Sigma Chemical Company, St. Louis, MO. Sodium azide was obtained from Fisher Scientific, Cincinnati, $\mathrm{OH}$.

Collection and separation of PMN. Venous blood was obtained from healthy adult donors according to the institution's informed consent policy. Heparin $(10 \mathrm{U} / \mathrm{ml})$ was used as the anticoagulant. PMN were isolated by Ficoll-Hypaque density centrifugation according to the method of Boyum (13) as modified by Ingraham et al. (14). PMN were resuspended in KRPG to a concentration of $1 \times 10^{7} \mathrm{PMN} / \mathrm{ml}$. After isolation the PMN were more than $95 \%$ viable by Trypan blue exclusion; LDH release was consistently less than $8 \%$.

Assays. Superoxide anion was measured according to the superoxide dismutase-inhibitable reduction of cytochrome $\mathrm{C}$ (15). Lactate dehydrogenase was measured by the method of Weening et al. (16). During the PMA exposure time study, a Pye-Unican spectrophotometer (SP-1800) was used for both assays. A Gilford response single beam spectrophotometer was used during the Vitamin E dose response study.

Protocol. Immediately after PMN collection and a 10-min incubation period at $37^{\circ} \mathrm{C}, \mathrm{PMN}\left(250 \mu \mathrm{l}\right.$ of $\left.1 \times 10^{7} \mathrm{PMN} / \mathrm{ml}\right)$ were added to $3 \mathrm{ml}$ polypropylene test tubes containing cytochrome $\mathrm{C}(119 \mu \mathrm{M})$, sodium azide ( $1 \mathrm{mM}$ ), and KRPG (amount to achieve total volume of $0.5 \mathrm{ml})$. Superoxide dismutase $(48 \mu \mathrm{g})$ was used as a control and all studies were done in triplicate. Vitamin E $(3.5 \mathrm{mg} / \mathrm{dl})$ or vehicle (equivalent concentration to that in which the vitamin $\mathrm{E}$ is suspended) was added and incubated in a shaking water bath for $10 \mathrm{~min}$ at $37^{\circ} \mathrm{C}$. As part of the dose-response study, the cells were washed after treatment with vitamin $\mathrm{E}$, vehicle, or KRPG and resuspended in buffer. The cell suspensions were then exposed to $50 \mathrm{ng} / \mathrm{ml}$ PMA. Initial 
Table 1. Vitamin E preparation

\begin{tabular}{lc}
\hline AT & $50.0 \mathrm{mg}$ \\
Ethyl alcohol 100 proof & $0.1 \mathrm{ml}$ \\
Propylene glycol & $0.1 \mathrm{ml}$ \\
Benzyl alcohol & $0.01 \mathrm{ml}$ \\
Sodium acetate trihydrate & $0.3 \mathrm{mg}$ \\
Glacial acetate acid & $9.0 \mathrm{mg}$ \\
Disodium acetate & $0.1 \mathrm{mg}$ \\
NaOH solution (10\%, to achieve $\mathrm{pH}$ & \\
$\quad 4 \pm 0.1)$ & \\
Water for injection (to achieve final & \\
volume of $1.0 \mathrm{ml})$ & \\
\hline
\end{tabular}

PMA exposure time studies were for 1,5 , and $10 \mathrm{~min}$. The PMA exposure time in subsequent vitamin $\mathrm{E}$ dose-response studies $(3.5,5.0$, and $10.0 \mathrm{mg} / \mathrm{dl}$ vitamin E) was $5 \mathrm{~min}$. After the specified exposure time to PMA, the reduction of cytochrome $\mathrm{C}$ was stopped by addition of ice-cold NEM $(0.5 \mathrm{ml})$. The tubes were centrifuged $\left(400 \times g, 5 \mathrm{~min}, 4^{\circ} \mathrm{C}\right)$ and supernatant absorptions read spectrophotometrically at $550 \mathrm{nM}$. The results were converted to $\mathrm{nM}$ reduced cytochrome $\mathrm{C} / 10^{7} \mathrm{PMN}$ using the extinction coefficient of $19.1 \times 10^{3} \mathrm{M}^{-1} \mathrm{~cm}^{-1}$. Supernatants were also assayed for LDH by adding $0.200 \mathrm{ml}$ to a cuvette containing $0.850 \mathrm{ml}$ pyruvic acid $(0.34 \mathrm{mM}$ in potassium phosphate buffer, $\mathrm{pH} 7.5$ ) and $0.025 \mathrm{ml}$ NADH (potassium phosphate buffer, $\mathrm{pH}$ 7.5). The OD at $340 \mathrm{mM}$ was observed continuously for $5 \mathrm{~min}$ at $25^{\circ} \mathrm{C}$. Slopes of the linear segment of the curve generated were compared to that generated for supernatants of PMN disrupted by sonication (three 10 -s bursts with 10 -s rest intervals, $0^{\circ} \mathrm{C}$; Heat systems, Ultrasonics, Inc., Farmingdale, NY, model W225, output setting of 3).

Data analysis. Statistical comparison of data was performed using analysis of variance with either multiple comparison or the least significant difference for a specific pair of means. Significance was defined at the $p<0.05$ level.

\section{RESULTS}

PMA exposure time study. Superoxide anion production after exposure to PMA for $0,1,5$, and $10 \mathrm{~min}$ is depicted in Figure 1. The amount of superoxide anion produced by $5 \mathrm{~min}$ was significantly less in the vitamin E-treated PMN $\left(76 \pm 15 \mathrm{nM} / 10^{7}\right.$ PMN) compared to the vehicle-treated PMN $(286 \pm 109 \mathrm{nM} /$ $\left.10^{7} \mathrm{PMN}\right)$. This trend continued through $10 \mathrm{~min}$ of PMA exposure with the amount of superoxide anion produced by the vitamin E-treated $\mathrm{PMN}$ being $226 \pm 18 \mathrm{nM} / 10^{7} \mathrm{PMN}$ versus $502 \pm 174 \mathrm{nM} / 10^{7} \mathrm{PMN}$ produced by vehicle-treated $\mathrm{PMN}(p$ $<0.05$ ).

LDH release from vehicle-treated PMN was twice that from vitamin E-treated PMN at all PMA exposure times (Fig. 2). After incubation for $10 \mathrm{~min}$ with vehicle and immediately before PMA exposure (time 0, Fig. 2), vehicle-treated PMN released $25 \pm$ $14 \% \mathrm{LDH}$ whereas vitamin E-treated PMN released $10 \pm 6 \%$ LDH. LDH release increased with PMA exposure so that by 5 min, $42 \pm 10 \% \mathrm{LDH}$ was released from vehicle-treated PMN At the same PMA exposure time, vitamin E-treated PMN released only $23 \pm 7 \% \mathrm{LDH}$. $\mathrm{LDH}$ release from untreated PMN exposed to PMA for 5 min was $11 \pm 4.5 \%$.

Vitamin $E$ dose-response study. Because of the significant difference in superoxide anion production between vitamin $\mathrm{E}$ and vehicle-treated PMN, we performed a dose-response curve using vitamin $\mathrm{E}$ concentrations which were demonstrated in vivo to increase the risk of infectious complications in premature infants (8). In the presence of $3.5 \mathrm{mg} / \mathrm{dl}$ vitamin $\mathrm{E}$, no significant difference in superoxide anion production by buffer-treated PMN was found (Fig. 3). At $10.0 \mathrm{mg} / \mathrm{dl}$, the amount of superoxide anion produced was significantly less from the vitamin $\mathrm{E}$ treated PMN $\left(108 \pm 62 \mathrm{nM} / 10^{7} \mathrm{PMN}\right)$ compared to buffer controls (325 $\left.\pm 109 \mathrm{nM} / 10^{7} \mathrm{PMN}\right)$ and vehicle-treated PMN

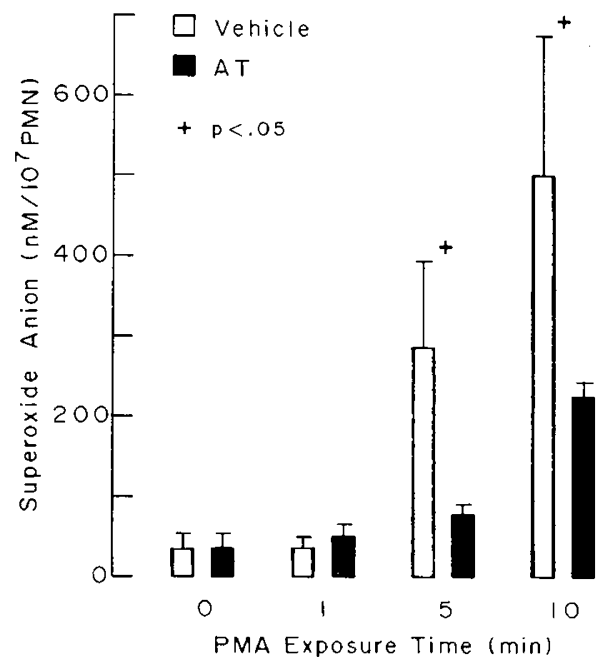

Fig. 1. Superoxide anion production-PMA exposure time study. The amount of superoxide anion produced (nM/10 $\mathrm{PMN}$ ) in the presence of vitamin E (AT) or vehicle is compared for $0,1,5$, and 10 min of PMA exposure. The bars depict the mean \pm 1 SD from seven experiments. Superoxide anion production is significantly lower by the AT-treated PMN at 5 and $10 \mathrm{~min}(p<0.05)$.

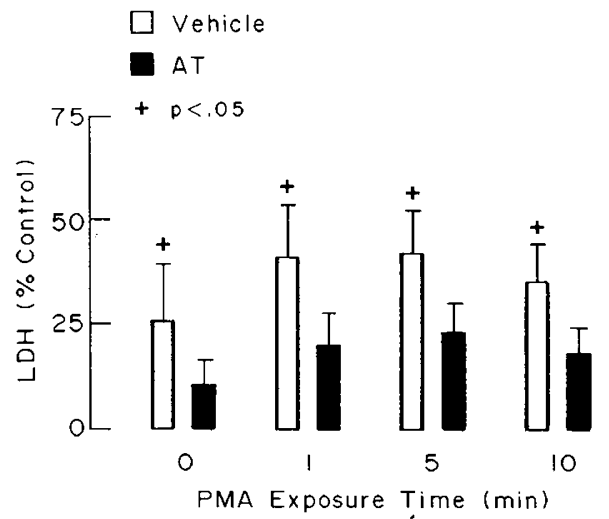

Fig. 2. LDH release-PMA exposure time study. The amount of $\mathrm{LDH}$ released at $0,1,5$, and $10 \mathrm{~min}$ is significantly lower at all time points from PMN treated with vitamin E (AT) compared to vehicle ( $p$ $<0.05$ ). The bars depict mean \pm 1 SD from seven experiments.

$\left(562 \pm 89 \mathrm{nM} / 10^{7} \mathrm{PMN}\right)$. The amount of superoxide anion produced at $5.0 \mathrm{mg} / \mathrm{dl}$ vitamin $\mathrm{E}$ was intermediate between that at 3.5 and $10.0 \mathrm{mg} / \mathrm{dl}$ and not significantly different from buffercontrols; however, the amount produced $\left(258 \pm 63 \mathrm{nM} / 10^{7}\right.$ PMN) was significantly less than that of the vehicle-treated PMN $\left(548 \pm 85 \mathrm{nM} / 10^{7} \mathrm{PMN}\right)$

$\mathrm{LDH}$ release at all three concentrations of vitamin $\mathrm{E}$ and vehicle were significantly elevated compared to buffer-treated PMN (Fig. 4). Because elevations in LDH release is associated with cell death that could account for diminished superoxide anion production, we incorporated a wash step into our protocol to remove vitamin $\mathrm{E}$ and vehicle from the solution surrounding the PMN before PMA exposure. LDH release was decreased to levels less than $12 \%$ in the buffer and vitamin E-treated PMN (Fig. 5). LDH release by vehicle-treated PMN was improved compared to the unwashed vehicle-treated PMN but continued to be significantly greater than buffer controls.

Superoxide anion production after washing vitamin $\mathrm{E}$ and vehicle from the reaction mixture are shown in Figure 6 . Vitamin E-treated PMN continued to release similar amounts of superoxide anion at $3.5 \mathrm{mg} / \mathrm{dl}(359 \pm 55 \mathrm{nM} / \mathrm{dl})$ compared to buffer controls $(359 \pm 55 \mathrm{nM} / \mathrm{dl})$. At 5.0 and $10.0 \mathrm{mg} / \mathrm{dl}$ vitamin $\mathrm{E}$, 


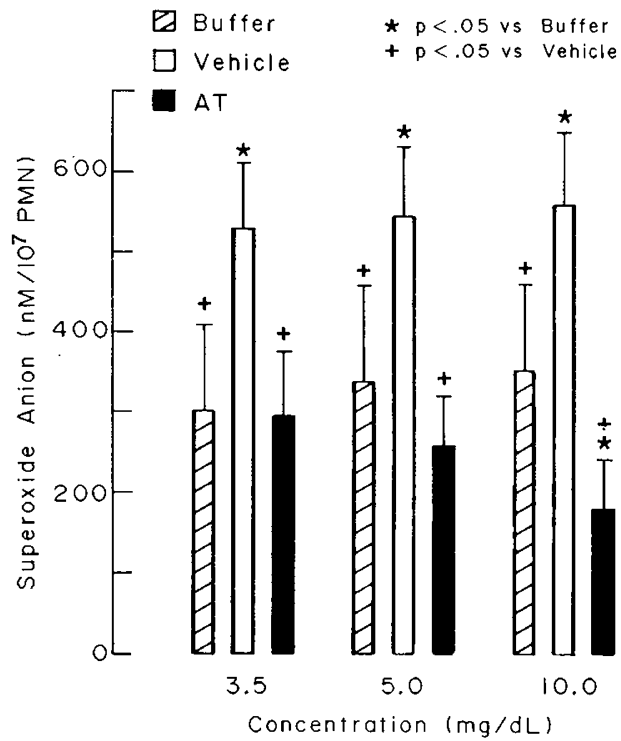

Fig. 3. Superoxide anion production-vitamin $\mathrm{E}$ dose-response with simultaneous exposure to vitamin E (AT) or vehicle and PMA. The amount of superoxide anion produced decreases with increasing concentrations of AT and becomes significantly lower at $10 \mathrm{mg} / \mathrm{dL} \mathrm{AT} \mathrm{com-}$ pared to buffer controls. Both buffer- and AT-treated PMN produce significantly less superoxide anion than vehicle-treated cells. The bars depict the mean \pm 1 SD from five experiments.

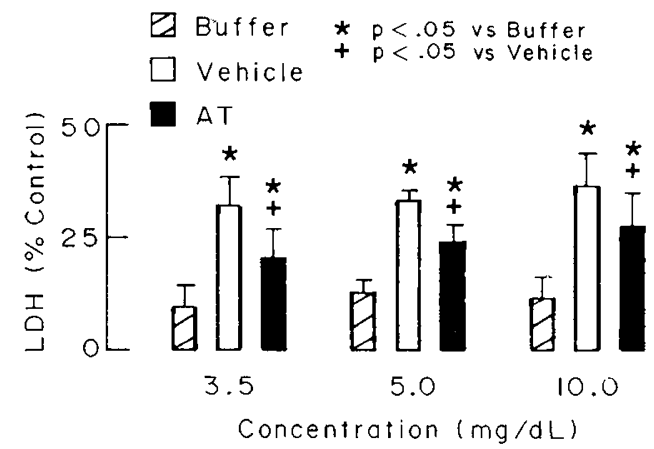

Fig. 4. LDH release-vitamin E dose response study with simultaneous exposure to vitamin E (AT) or vehicle and PMA. LDH release is significantly increased in both AT- and vehicle-treated PMN (all concentrations) compared to buffer controls $(p<0.05)$. AT-treated cells release significantly less LDH then vehicle-treated PMN. The bars depict mean $\pm 1 \mathrm{SD}$ from five experiments.

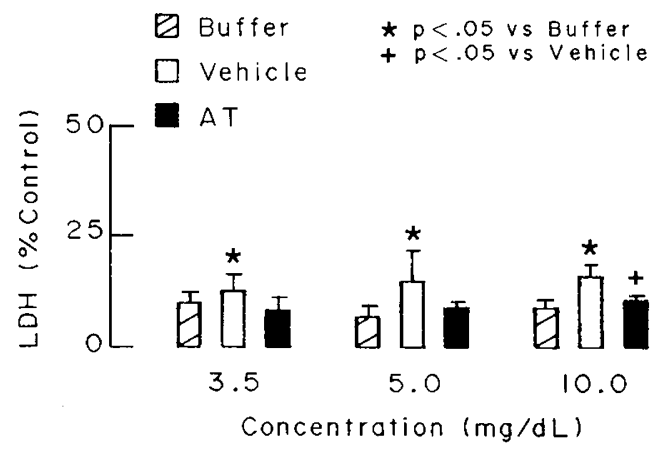

Fig. 5. LDH release-vitamin E dose response study with sequential exposure to vitamin E (AT) or vehicle and PMA. LDH release is similar for buffer- and AT-treated cells except at $10.0 \mathrm{mg} / \mathrm{dl} \mathrm{AT}$ (small but significant difference). $\mathrm{LDH}$ release by vehicle-treated cells is significantly greater than by buffer-treated cells at $3.5,5.0$, and $10.0 \mathrm{mg} / \mathrm{dl}$ of vehicle. The bars depict the mean \pm 1 SD from five experiments.

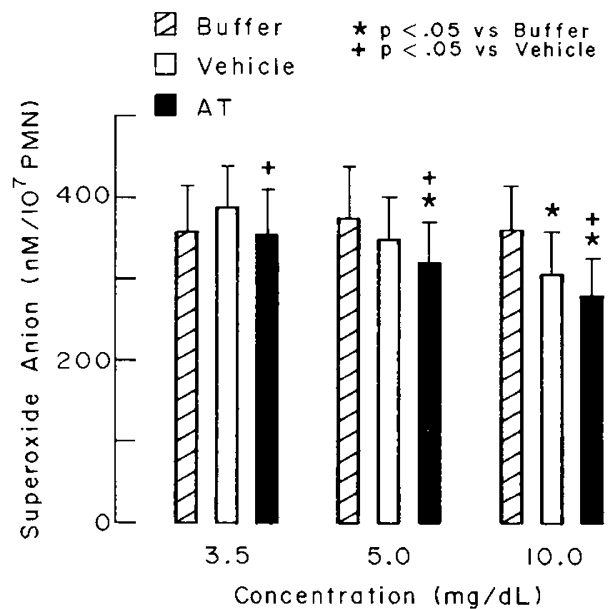

Fig. 6. Superoxide anion production-vitamin $E$ dose response study with sequential exposure to vitamin E (AT) or vehicle and PMA. Superoxide anion production is significantly lower by AT-treated PMN than buffer controls at AT concentrations of 5.0 and $10.0 \mathrm{mg} / \mathrm{dl}$. At $10.0 \mathrm{mg} /$ $\mathrm{dl}$ of vehicle, superoxide anion production is significantly lower than buffer controls and significantly greater than AT-treated PMN. The bars depict the mean \pm 1 SD from five experiments.

however, significantly less superoxide anion was produced (321 \pm 49 and $278 \pm 48 \mathrm{nM} / 10^{7} \mathrm{PMN}$, respectively). Compared to vehicle-treated PMN, vitamin E-treated PMN produced less superoxide anion at all concentrations studied (Fig. 6). At a vehicle concentration equivalent to that in which $10 \mathrm{mg} / \mathrm{dl}$ of vitamin $\mathrm{E}$ is suspended, superoxide anion production was also significantly less than superoxide anion production from buffertreated PMN

\section{DISCUSSION}

Superoxide anion is an oxygen radical important for bacterial killing by polymorphonuclear leukocytes $(15,17)$. In the presence of pharmacologic levels of vitamin E, the ability of PMN to migrate toward a chemoattractant (9), destroy bacteria (10), and produce oxygen radicals $(11,12)$ is diminished. Baehner et al. (11) supplemented the diet of human volunteers with megadoses of vitamin $E$ to achieve vitamin $E$ levels twice normal; diminished bactericidal activity was found and was partly due to decreased hydrogen peroxide release. Shigeoka et al. (12) incubated polymorphonuclear leukocytes from two stressed neonates and adult controls with pharmacologic concentrations of vitamin E. A significant decrease in chemiluminescence (measure of total oxygen radical generation) was found and was most significant in leukocytes from stressed neonates.

Baehner et al. (11) did not show decreased superoxide anion production by PMN obtained from adult volunteers whose diets were supplemented with vitamin E. Our results may differ because we studied PMN exposed to $3.5-10 \mathrm{mg} / \mathrm{dl}$ vitamin $\mathrm{E}$ whereas Baehner et al. (11) studied PMN exposed to 1.77-1.85 $\mathrm{mg} / \mathrm{dl}$ vitamin $\mathrm{E}$. In addition, variation in experimental methods may have contributed to the differences found.

We treated polymorphonuclear leukocytes with levels of the vitamin $\mathrm{E}$ preparation reported by Johnson et al. (8) to be associated with a significant increase in infections in vitamin Etreated low birth weight infants. Our results demonstrate that vitamin E-treated PMN produce significantly less superoxide anion compared to vehicle-treated cells at 5 and 10 min of PMA exposure. Our dose-response studies demonstrated that at levels of vitamin $\mathrm{E}$ considered upper normal $(3.5 \mathrm{mg} / \mathrm{dl})$, superoxide 
anion production is similar to buffer-treated controls (Fig. 3 and 6 ). However, superoxide anion production was significantly decreased at 5.0 and $10.0 \mathrm{mg} / \mathrm{dl}$ vitamin E compared to buffertreated control cells (Fig. 6). Because results were unchanged after washing the detergents in the vehicle from the reaction mixture, we propose that this effect is due to the vitamin $\mathrm{E}$ incorporated into the cell membrane.

As adult and neonatal leukocytes have similar superoxide anion generating activity (18), one may assume that superoxide anion production by neonatal leukocytes will also be depressed by pharmacologic levels of vitamin E. Although the absolute decrease in superoxide anion production is only $11 \%$ at $5.0 \mathrm{mg} /$ $\mathrm{dl}$ vitamin $\mathrm{E}$ and $23 \%$ at $10.0 \mathrm{mg} / \mathrm{dl}$, in the presence of a limited neonatal host defense response $(12,19,20)$, the neonate may be at heightened risk for infection. The mechanism of this vitamin $E$ effect is unclear. As vitamin $E$ is closely bound to arachidonate in the proximity of membrane-bound proteins (21), it is reasonable to hypothesize that pharmacologic concentrations of vitamin $\mathrm{E}$ may alter the membrane-bound components of the superoxide anion generating system thereby affecting its function.

The vehicle for vitamin $E$ results in markedly increased superoxide anion production by PMN stimulated by PMA. The effect is mitigated by washing the vehicle from the reaction mixture before PMA exposure. Because LDH and superoxide anion production are both significantly increased when vehicle and PMA are concurrently present, it may be that some component of the vehicle primes the cell such that PMA more readily activates the enzymatic pathway responsible for superoxide anion production.

The protective function of vitamin $\mathrm{E}$ against oxidative attack and vehicle is demonstrated in Figures 2 and 4. In the presence of high concentrations of superoxide anion after stimulation of leukocytes exposed to vehicle alone, $\mathrm{LDH}$ release was markedly elevated. However, with the addition of vitamin E significantly less $\mathrm{LDH}$ release occurred (Fig. 4). This suggests that vitamin $\mathrm{E}$ protects the cell membrane of PMN from the action of the vehicle and local oxygen radicals.

In summary, in vitro exposure of PMN to pharmacologic levels of vitamin $E$ is associated with significantly decreased superoxide anion production. These results may help explain the previous report of diminished hydrogen peroxide release with excess vitamin $\mathrm{E}$ because hydrogen peroxide is derived intracellularly from superoxide anion $(11,18)$. This finding may also explain, in part, the observation of Johnson et al. (8) that low birth weight infants maintained at pharmacologic levels of vitamin $E$ are at increased risk for developing sepsis and necrotizing enterocolitis.

$A C K N O W L E D G E M E N T$. The authors thank Carol Blue for preparation of this manuscript.

\section{REFERENCES}

1. Hittner HM, Godel LB, Rudolph AJ 1981 Retrolental fibroplasia: efficiency of vitamin $E$ in a double-blind clinical study of preterm infants. $N$ Engl $J$ Med 305:1365-1371

2. Finer NN, Grant G, Schindler RF 1982 Effect of intramuscular vitamin E on frequency and severity of retrolental fibroplasia. Lancet 2:1087-1091

3. Owens WC, Owens EU 1949 Retrolental fibroplasia in premature infants. Studies on the prophylaxis of the disease. The use of alpha-tocopheryl acetate. Am J Ophthalmol 32:1831

4. Chiswick ML, Johnson M, Woodhall C 1983 Protective effect of vitamin $\mathrm{E}$ ( $d L$-alpha-tocopherol) against intraventricular hemorrhage in premature babies. Br Med J 287:81-84

5. Speer ME, Blifield C, Rudolph AJ 1984 Intraventricular hemorrhage and vitamin $E$ in the very low birth weight infant: evidence for efficacy of early intramuscular vitamin E administration. Pediatrics 74:1107-1112

6. Sunil S, Toner N, Davies J, Bogle S, Chiswick M 1987 Vitamin E supplementation reduces frequency of periventricular hemorrhage in very preterm babies. Lancet 1:466-471

7. Hittner HM, Speer ME, Rudolph AJ 1984 Retrolental fibroplasia and vitamin $\mathrm{E}$ in the preterm infant-comparison of oral versus intramuscular:oral administration. Pediatrics 73:238-249

8. Johnson L, Bowen FW Jr, Abbasi S 1985 Relationship of prolonged pharmacologic serum levels of vitamin $\mathrm{E}$ to incidence of sepsis and necrotizing enterocolitis in infants with birth weight 1500 grams or less. Pediatrics 75:619-638

9. Goetzl EJ 1980 Vitamin E modulates the lipoxygenation of arachidonic acid in leukocytes. Nature 288:183-185

10. Prasad JS 1980 Effect of vitamin E supplementation on leukocyte function Am J Clin Nutr 33:606-608

11. Baehner RL, Boxer LA, Ingraham LM 1982 The influence of vitamin E on human polymorphonuclear metabolism and function. Ann NY Acad Sci 293:237-250

12. Shigeoka AO, Charette RP, Wyman ML 1981 Defective oxidative metabolic response of neutrophils from stressed neonates. J Pediatr 98:392-398

13. Boyum A 1968 Isolation of mononuclear cells and granulocytes from human blood. Isolation of mononuclear cells by one centrifugation and of granulocytes by combining centrifugation and sedimentaton. Scan J Clin Lab Invest 21(suppl 97):77-89

14. Ingraham L, Coates TD, Allen JM 1982 Metabolic membrane and functional responses of human polymorphonuclear leukocytes to platelet activating factor. Blood 59:1259-1266

15. Babior BM, Kipnes RS, Curnutte ST 1973 The production by leukocytes of superoxide, a potential bactericidal agent. J Clin Invest 52:741-744

16. Weening RS, Stricker L, Roos D 1979 Phagocytosis. In: Weening RS (ed) Neutrophil Function and metabolism in Health and Disease. Academisch Proctschrift, Amsterdam, pp 61-73

17. Fantone JC, Ward PA 1982 Role of oxygen-derived free radicals and metabolites in leukocyte-dependent inflammatory reactions. Am J Pathol 107:397418

18. Strauss RG, Snyder EL 1983 Activation and activity of the superoxidegenerating system of neutrophils from human infants. Pediatr Res 17:662664

19. Miller ME: 1978 Host defenses in the neonate. In: Oliver MC Jr (ed) Monographs in Neonatology. Grune and Stratton, New York, pp 59-72

20. Wright W, Amk B, Herbert J 1975 Decreased bactericidal activity of leukocytes of stressed newborn infants. Pediatrics 56:579-584

21. Molennaar L, Hulstaert CE, Hardonk MJ 1980 Role in function and uitrastructure of cellular membranes. In: Machlin LJ (ed) Vitamin E: A Comprehensive Treatise. Marcel Dekkar, New York, pp 372-389 